\title{
Strategi Usaha Biro Perjalanan Wisata Sumatera Barat dalam Menghadapi Krisis Pandemi Covid-19
}

\author{
Rini Eka Sari*1, Novi Yanita ${ }^{2}$, dan Sepri Neswardi ${ }^{3}$ \\ ${ }^{1,2,3}$ Politeknik Negeri Padang \\ *E-mail: rini@pnp.ac.id
}

\begin{abstract}
The study is aimed to formulate the stategies of West Sumatera's Tour Operator in facing the COVID-19 Pandemic crisis. The limitation of mobilization in travelling to break the chain of the spreading of COVID-19 Pandemic, has paralyzed the Tour operator business in all regions including in West Sumatera. The strategies are formulated using SWOT analysis (Strength, Weakness, Opportunity, Thread), by minimizing the weakness and thread and maximizing the strength and opportunity. Research data collection is conducted through in depth interview with some tour operator business stakeholders in West Sumatera, using purposive sampling method. Then, the data is analyzed descriptively, by noticing the strength, weakness, opportunity and thread factors of tour operator business in West Sumatera to formulate the strategies in facing the COVID-19 Pandemic crisis. The result reveals that there are several strategies conducted by tour operators in West Sumatera in the stage of short-term strategies, medium term strategies and long-term strategies to sustain the business.
\end{abstract}

Keywords: strategies, business, tour operator, West Sumatera, COVID-19 pandemic

\begin{abstract}
Abstrak
Penelitian ini bertujuan untuk merumuskan strategi usaha Biro Perjalanan Wisata (BPW) di Sumatera Barat dalam menghadapi krisis Pandemi COVID-19. Terhentinya mobilisasi dalam melakukan perjalanan wisata untuk memutus mata rantai penyebaran Pandemi COVID-19 telah melumpuhkan usaha BPW diseluruh daerah tak terkecuali di Sumatera Barat. Strategi dirumuskan dengan menggunakan analisis SWOT (Strength, Weakness, Opportunity, Thread), dengan memperkecil kelemahan dan ancaman serta memperbesar kekuatan dan peluang yang ada. Pengumpulan data penelitian dilakukan melalui wawancara dengan beberapa stakeholder pelaku usaha BPW di Sumatera Barat dengan menggunakan metode purposive sampling. Selanjutnya data yang terkumpul dianalisis secara deskriptif, dengan memperhatikan faktor kekuatan, kelemahan, peluang dan ancaman yang dimiliki oleh BPW di Sumatera Barat untuk merumuskan strategi dalam menghadapi krisis Pandemi COVID-19. Hasil penelitian menunjukkan bahwa terdapat beberapa strategi yang bisa dilakukan oleh usaha BPW Sumatera Barat yaitu strategi jangka pendek, jangka meneangah dan jangka panjang demi keberlangsungan usahanya.
\end{abstract}

Kata Kunci:Strategi, usaha, Biro Perjalanan Wisata, Sumatera Barat, Pandemi COVID-19

\section{Pendahuluan}

Kegiatan kepariwisataan terbukti telah menjadi penyumbang devisa bagi negara Indonesia. Pada tahun 2019, sektor pariwisata memberikan kontribusi sebagai pemasukan terbesar kedua di Indonesia. Usaha pariwisata yang menjadi penggerak kegiatan kepariwisataan dapat memberikan multiplier effect terhadap berbagai sektor lainnya. Aktivitas pariwisata telah menyerap langsung sekitar 10\% (13 juta pekerja) dari total tenaga kerja nasional padatahun 2019. Sektor penyediaan akomodasi, serta makan minum telah berkontribusi menyerap tenaga kerja sebesar 7\% (8,5 juta pekerja) dari total tenaga kerja nasional (Revindo dkk, 2020). Merebaknya Pandemi COVID-19, berdampak pada semua kegiatan secara global, terutama kegiatan pariwisata. Jumlah wisatawan turun drastis seiring dengan pembatasan perjalanan, baik dengan moda transportasi darat, laut dan udara. Kondisi ini semakin memburuk semenjak diberlakukannya social distancing, physical distancing, dan Pembatasan Sosial Berskala Besar (PSBB) untuk memutus mata 
rantai penyebaran Pandemi COVID-19. Semua jenis usaha pariwisata di dunia termasuk di Indonesia terdampak oleh kondisi ini.

Sumatera Barat sebagai salah satu destinasi pariwisata andalan di Indonesia juga merasakan dampak dari penyebaran Pandemi COVID-19 ini. Para pelaku usaha pariwisata di Sumatera Barat sangat terpukul, termasuk usaha BPW dan travel agent. Sebagian besar memilih tutup sementara dan merumahkan karyawannya. Kondisi ini tentu saja akan berdampak buruk bagi pemilik usaha dan pekerja yang bernaung pada usaha tersebut. Kejadian ini bisa saja menghancurkan organisasi dan karyawan, produk, jasa, kondisi keuangan dan reputasi. Memperhatikan kondisi yang sedang terjadi, tentunya diperlukan strategi bagi pelaku usaha pariwisata khususnya BPW Sumatera Barat dalam menghadapi krisis Pandemi COVID-19 ini, agar dapat meminimalisir dampaknya dan dapat bangkit kembali dari krisis tersebut. Krisis menurut Prayudi (2008) adalah suatu kejadian besar dan tidak terduga yang memiliki potensi untuk berdampak negatif. Menurut Jaques (2009), krisis dapat menyebabkan isu yang berkepanjangan dan merusak, oleh sebab itu organisasi yang tetap berada pada penanganan post krisis yang konvensional, akan mengalami resiko kegagalan dalam proses pengelolaan masalah post krisis dalam jangka panjang.

Selain strategi, keahlian dalam mengelola sebuah krisis sangat diperlukan dalam menghadapi kondisi ini. Henderson (2007) mendefinisikan :

Crisis management is a term which describes the responses to a crisis by organizations affected and their attempts to exercise some control over its progress and outcomes. It can be conceived of as a special campaign in which human, financial and other available resources are made use of in order to combat a situation of great difficulty. The ultimate aims are to overcome the dangers posed by the crisis and minimize damage.

Manajemen krisis didasarkan atas bagaimana menghadapi krisis (crisis bargaining and negotiation), membuat keputusan di saat krisis (crisis decision making), dan memantau perkembangan krisis (crisis dynamics). Manajemen bertanggung jawab untuk mencari pemecah masalah dari krisis yang muncul dengan menggunakan strategi manajemen krisis yang mungkin dilakukan (Iriantara, 2004). Tujuan utama dari manajemen krisis adalah untuk mengambil langkah terstuktur dan pencegahan untuk memastikan bahwa hasil negative yang potensialdari masalah atau krisis baik nama dan citra dari organisasi dikontrol dan dibatasi sebanyak mungkin, sehingga pengikisan reputasi perusahaan merupakan bahaya terbesar dalan sebuah krisis (Koster, \& Norton, 2004). Menurut Kasali (1994), terdapat tiga strategi generik yang dapat digunakan untuk menangani krisis, yaitu:

1. Strategi defensive

Diterapkan apabila cakupan isu masih belum spesifik mengenai individu, produk atau perusahaan, langkah-langkah yang dapat ditempuh seperti mengulur waktu, tidak melakukan apa-apa, dan membentengi diri dengan kuat.

2. Strategi adaptif

Diterapkan apabila isu atau gejala munculnya isu sudah mulai tampak, baik mengarah pada isu bersifat umum maupun spesifik. Dampak isu biasanya makin besar dan jika dibiarkan, isu tersebutakan menjadi tidak terkendali. Langkah yang ditempuh seperti mengubah kebijakan, modifikasi aspek operasional, kompromi, dan meluruskan citra.

3. Strategi dinamis 
Diterapkan apabila cakupan isu sudah mengarah ke hal yang lebih spesifik mengenai suatu produk, individu, atau perusahaan. Diperlukan langkah antisipasi yang menetralkan suasana dan mengembalikan isu ke arah yang positif.Langkah yang dapat ditempuh adalah investasi baru, menjual saham, meluncurkan produk baru, menarik peredaran produk lama, menggandeng kekuasaan, dan melempar isu baru untuk mengalihkan perhatian publik.

Bong, dkk (2019) menjelaskan bahwa AICST (APEC Internal Center for Sustainable Tourism) mengusulkan empat fase penanganan manajemen resiko dan krisis dengan metode 4R (Reduction, Readiness, Response, Recovery) yaitu :

1. Perencanaan program untuk mengurangi resiko (Reduction) yang terdiri dari:

a. Crisis Awarness, yaitu mempersiapkan program-program kesadaran akan resiko bencana dari berbagai kemungkinan yang bisa terjadi.

b. Political Awareness, yaitu menjalin hubungan erat dengan aparat keamanan dan kepolisian setempat serta instansi-instansi pemerintah daerah yang berkaitan langsuang dengan masalah resiko keamanan (safety), keselamatan (security), dan kenyamanan (surety) para pelancong industry pariwisata.

c. Standard Operating Procedures yang berkaitan dengan keamanan, keselamatan dan kenyamanan lingkungan pariwisata, baik untuk kepentingan pelayanan yang ditujukan kepada para wisatawan, maupun karyawan sendiri termasuk masyarakat sekitar.

2. Persiapan program siaga (Readiness) terdiri dari :

a. Crisis Management Plan, kesiagaan yang diawali dengan perencanaan yang komprehensif dan realistis, termasuk dana dan fasilitas pendukung yang memadai serta tenaga manusia yang terlatih

b. Tourism Planning, perencanaan berbagai program pariwisata dan perencanaan manajemen resiko dan krisis tidak dapat dipisahkan karena bergerak seiring sejalan.

c. Health and Safety Measures, ukuran resiko apabila terjadi krisis dan bencana harus diestimasi dalam perencanaan manajemen resiko.

3. Program persiapan response (Response) yang terdiri dari :

a. Emergency Response Procedure, kesiapan dengan prosedur response emergenc.

b. Investigation, penelitian sumber-sumber dari setiap krisis dan bencana apabila terjadi musibah yang tidak diinginkan.

c. Family Assistance and Communication, mempersiapkan pusat komunikasi apabila terjadi bencana agar keluarga konban terinformasikan dan komunikasi kepada media massa bisa terpusat dan terkendali.

4. Program Pengembalian ke kondisi semula (Recovery) yang terdiri dari :

a. Business Continuity Plan, perencanaan pemulihan dari organisasi pariwisata dan pemerintahan daerah agar masyarakat bisa beaktifitas kembali seperti semula dalam jangka waktu dan biaya investasi kembali yang ditentukan.

b. Human resources and Debriefing, koordinasi para petugas dalam program pemulihan agar terkendali dan terkelola dengan baik.

Penelitian ini bertujuan untuk merumuskan strategi dari usaha BPW Sumatera Barat dalam menghadapi krisis Pandemi COVID-19. Kajian tentang strategi yang dapat 
dilakukan oleh BPW ini dibagi menjadi 3 tahapan yaitu strategi jangka pendek, jangka menengah dan jangka panjang. Pembagian ini sangat berguna untuk memproyeksikan apa saja aksi yang mungkin dapat dilakukan oleh pelaku usaha BPWdalam menghadapi krisis Pandemi COVID-19 ini untuk masa sekarang dan juga di masa yang akan datang, sehingga usaha BPW dapat menggeliat kembali setelah Pandemi COVID-19 ini berakhir.

\section{Metodologi}

Penelitian ini menggunakan metode kualitatif. Informan penelitian dipilih dengan metode purposive sampling yaitu menetapkan informan berdasarkan pertimbangan tertentu yang mana informan dianggap dapat membantu tercapainya tujuan dari penelitian ini. Data yang dikumpulkan didapat dari stakeholder pelaku usaha BPW yang berada di Sumatera Barat terkait informasi mengenai kondisi BPW dan strategi para pelaku usaha BPW dalam menghadapi krisis pandemi COVID-19. Data penelitian dikumpulkan dengan menggunakan teknik wawancara kepada informan yang terkait dengan usaha BPW di Sumatera Barat. Pengumpulan data dimulai dari bulan Mei 2020 sampai dengan bulan Agustus 2020. Pertanyaan yang diajukan kepada informan adalah mengenai faktor internal berupa kekuatan dan kelemahan serta pertanyaan mengenai faktor eksternal (peluang dan ancaman) pelaku usaha BPW Sumatera Barat pada masa Pandemi COVID19 ini.

Analisis data dalam penelitian ini dilakukan secara deskriptif melalui proses reduksi data, penyajian data dan verifikasi data. Data yang telah terkumpul kemudian diolah dengan menggunakan teknik analisis SWOT berupa matriks. Matriks SWOT digunakan untuk merumuskan strategi pelaku usaha BPW di Sumatera Barat dalam menghadapi krisis Pandemi COVID-19, dengan meminimalkan kelemahan dan ancaman serta memaksimalkan kekuatan dan peluang yang ada. Menurut Rangkuti (2006), matriks SWOT dibangun berdasarkan hasil analisis factor-faktor strategis baik eksternal maupun internal yang terdiri atas faktor peluang, ancaman, kekuatan dan kelemahan. Matriks ini dapat menghasilkan empat kemungkinan altenatif strategi yaitu: Strategi SO (Strength and Oppurtunity) merupakan strategi yang dibuat dengan memanfaatkan seluruh kekuatan untuk merebut dan memanfaatkan peluang sebesar- besarnya. Strategi ST (Strength and Threat) merupakan strategi dalam menggunakan kekuatan yang dimiliki untuk mengatasi ancaman.Strategi WO (Weakness and Oppurtunity) adalah strategi yang diterapkan berdasarkan pemanfaatan peluang yang ada dengan cara meminimalkan kelemahan yang ada. Strategi WT (Weakness and Threat) merupakan strategi berdasarkan kegiatan yang bersifat defensif dan berusaha meminimalkan kelemahan yang ada serta menghindari ancaman. Setelah didapatkan empat set alternatif strategi, kemudian akan dikategorikan lagi menjadi strategi jangka pendek, strategi menengah dan juga strategi jangka panjang.

\section{Hasil dan Pembahasan}

Dari hasil pengumpulan data dengan beberapa informan didapatkan informasi berupa faktor internal berupa kekuatan dan kelemahan yang dimiliki BPW dan faktor eksternal berupa peluang dan ancaman yang dihadapi oleh usaha BPW Sumatera Barat di masa Pandemi COVID-19. Setelah data didapatkan, kemudian dilakukan analisis SWOT untuk mendapatkan 4 set alternatif strategi seperti yang terlihat pada tabel berikut : 


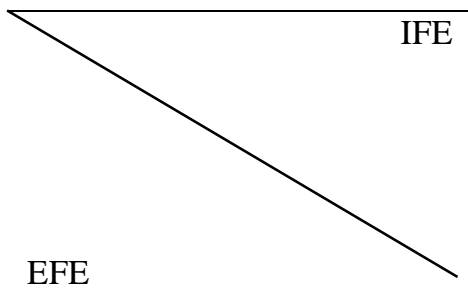

PELUANG (O)

Tingginya Animo masyarakat ditunjang dengan terjangkaunya harga tiket pesawat serta adanya jaminan dari pemerintah provinsi tentang protokol pencegahan COVID-19

\section{ANCAMAN (T)}

T1. Pandemi yang berkepanjangan dan kondisi yang tidak dapat diprediksi membuat rendahnya kunjungan wisatawan ke Sumatera Barat

T2. Peraturan pemerintah yang sering berubah sesuai kondisi dan tidak adanya Solusi Signifikan dari pemerintah

\section{KEKUATAN (S)}

Berkomitmen memberikan yang terbaik kepada konsumen dengan meningkatkan pelayanan, serta melakukan evaluasi diri sehingga tingkat kepercayaan konsumen semakin tinggi dan memanfaatkan pasar local.

1. Tetap menjaga komitmen perusahaan dalam memberikan pelayanan terbaik saat kondisi mulai normal dan memanfaatkan peluang jaminan pemerintah provinsi tentang protocol pencegahan COVID-19.

2. Menjaga Kualitas Produk dan Pelayanan untuk dapat mempertahankan tingkat kepercayaan konsumen terhadap perusahaan dengan memanfaatkan kebijakan pemerintah provinsi .

3. Melakukan evaluasi diri dengan cara memperbaiki segala aspek internal perusahan seperti, manajemen dan administrasi, cash flow, produk dan pelayanan.

4. Menyediakan asuransi perjalanan dan menambahakan kegiatan protocol kesehatan ke dalam SOP pelayanan.

5. Menciptakan paket wisata yang diperuntukkan bagi pasar domestic dan membuat paket konsorsium dengan relasi bisnis.

1. Mengoptimalkan peran Public Relations untuk meningkatkan minat wisatawan berkunjung ke Sumatera Barat melalui healthcampaign dan sosialisasi khususnya kepada pasar domestik.

2. Memanfaatkan sumber daya perusahaan secara optimal untuk dapat mengatasi permasalahaan yang ada dengan tetap berkoordinasi dengan pemerintah provinsi.

3. Meningkatkan kualitas SDM dengan mengikuti berbagai pelatihan kerja khususnya bidang manajemen krisis dalam industri pariwisata.

4. Memanfaatkan hubungan baik dengan relasi bisnis dalam segala hal, termasuk berbagi informasi terkait kebijakan pemerintah.

\section{KELEaMAHAN (W)}

Masalah keuangan, dan tidak adanya diversifikasi usaha serta adanya pengurangan SDM perusahaan.

1. Merancang strategi promosi dalam sebuah konsorsium seperti memberikan harga khusus, memanfaatkan media online dan melakukan sales call.

2. Menurunkan Target Perusahaan menjadi lebih realistis dengan kondisi pandemic COVID-19.

3. Melakukan diversifikasi usaha dengan cara merancang paket wisata minat khusus dengan tetap mempertimbangkan aspek kesehatan dalam masa pandemi COVID-19 dan membuat paket wisata virtual.

4. Melakukan restrukturisasi manajemen perusahaan dan mengoptimalkan SDM yang ada.

Sumber: Diolah Penulis, 2020 
Pada tabel di atas terlihat hasil analisis SWOT rumusan strategi bagi BPW di Sumatera Barat, yang kemudian strategi tersebut dikelompokkan menjadi tiga yaitu:

1. Strategi jangka pendek;

a. Tetap menjaga komitmen perusahaan dalam memberikan pelayanan terbaik saat kondisi mulai normal dan memanfaatkan peluang jaminan pemerintah provinsi tentang protokol pencegahan COVID-19, tetap optimis bahwa sektor pariwisata akan segera pulih. Hal ini sangat penting dilakukan oleh BPW di Sumatera Barat karena komitmen dari perusahaan serta pelayanan yang baik terhadap konsumen merupakan kunci dari kerberhasilan sebuah usaha.

b. Menjaga Kualitas Produk dan Pelayanan untuk dapat mempertahankan tingkat kepercayaan konsumen terhadap perusahaan dengan memanfaatkan kebijakan pemerintah provinsi dan besarnya kemungkinan pariwisata pulih kembali. Kualitas produk dan pelayanan adalah aspek yang penting dalam usaha di bidang jasa, sehingga BPW sebaiknya bisa menjaga aspek tersebut untuk meningkatkan kepercayaan konsumen, apalagi pada masa sulit seperti kondisi Pandemi COVID19 ini.

c. Melakukan evaluasi diri dengan cara memperbaiki segala aspek internal perusahan seperti, manajemen dan administrasi, cash flow, produk dan pelayanan.

d. Memanfaatkan asset yang dimiliki agar perusahaan dapat terus beroperasi dan melakukan restrukturisasi manajemen perusahaan serta mengoptimalkan SDM yang ada

e. Menurunkan target perusahaan menjadi lebih realistis dengan mempertimbangkan kondisi Pandemi COVID-19

f. Memanfaatkan kebijakan penangguhan pembayaran listrik dan kredit usaha bagi BPW

2. Strategi jangka menengah

a. Menyediakan asuransi perjalanan dan menambahkan kegiatan protokol kesehatan ke dalam SOP pelayanan.

b. Menciptakan paket wisata yang diperuntukkan bagi pasar domestik dan membuat paket konsorsium dengan relasi bisnis

c. Merancang strategi promosi dalam sebuah konsorsium seperti memberikan harga khusus, memanfaatkan media online dan melakukan sales call.

d. Melakukan diversifikasi usaha dengan cara merancang paket wisata minat khusus dengan tetap mempertimbangkan aspek kesehatan dalam masa pandemic COVID19 dan membuat paket wisata virtual.

e. Memanfaatkan sumber daya perusahaan secara optimal untuk dapat mengatasi permasalahaan yang ada dengan tetap berkoordinasi dengan pemerintah provinsi serta berupaya terus mengikuti perkembangan kebijakan pemerintah dan memanfaatkan kebijakan yang dapat menguntungkan perusahaan

f. Memanfaatkan hubungan baik dengan relasi bisnis dalam segala hal, termasuk berbagi informasi terkait kebijakan pemerintah.

3. Strategi jangka panjang

a. Mengupayakan peluang pengembangan usaha baik yang masih di dalam bidang pariwisata maupun bidang lainnya. 
b. Mengoptimalkan peran Public Relations untuk meningkatkan minat wisatawan berkunjung ke Sumatera Barat melalui health campaign dan sosialisasi khususnya kepada pasar domestik.

c. Meningkatkan kualitas SDM dengan mengikuti berbagai pelatihan kerja khususnya bidang manajemen krisis dalam industri pariwisata.

d. Mengupayakan untuk mendapatkan tambahan modal usaha melalui kerjasama dengan mitra

e. Melakukan pendekatan kepada pemerintah dalam upaya pengembangan usaha.

Strategi jangka pendek merupakan mitigasi terhadap krisis, yang dilakukan guna menangani kondisi BPW dalam waktu yang cepat sehingga dapat membenahi urusan internal perusahaan. Strategi jangka menengah merupakan kesiapsiagaan dan respon terhadap krisis, yang dilakukan dalam upaya menggerakkan kembali bisnis BPW dengan memperhatikan protokol kesehatan. Sementara strategi jangka panjang merupakan upaya yang dilakukan dalam tahap pemulihan krisis.

\section{Kesimpulan}

Berdasarkan hasil analisis SWOT dapat disimpulkan bahwa Biro Perjalanan Wisata Sumatera Barat dapat menjalankan strategi jangka pendek untuk membenahi internal perusahaan. Sementara untuk strategi jangka menengah dapat diterapkan secara bertahap dalam upaya untuk memulai kembali aktifitas usaha BPW setelah adanya kebijakan untuk menutup sementara atau merumahkan karyawan, berupa promosi paket wisata untuk wisatawan lokal dan domestik serta merancang paket wisata konsorsium dan paket wisata virtual. Strategi jangka panjang dapat direncanakan untuk pengembangan usaha BPW Sumatera Barat setelah Pandemi COVID-19 ini berakhir, dengan mengoptimalkan aspek sanitasi dan penerapan protokol kesehatan dalam segala aktifitas operasional usaha BPW.

\section{Saran}

Penelitian ini merupakan penelitian awal dari kondisi krisis yang terjadi pada usaha BPW saat penyebaran Pandemi COVID-19 di Sumatera Barat. Diharapkan setelah penelitian ini akan ada penelitian lebih lanjut tentang standar operasional pengembangan usaha BPW di masa setelah berakhirnya Pandemi COVID-19.

\section{Ucapan Terimakasih}

Penelitian ini didanai oleh danaDIPA Politeknik Negeri Padang tahun anggaran 2020 dengan nomor kontrak 259/ PL9.1.5/PG/2020. Kami mengucapkan terimakasih kepada Pusat Penelitian dan Pengabdian kepada Masyarakat Politeknik Negeri Padang, karena penelitian ini dapat terlaksana atas dukungan dana yang diberikan.

\section{Daftar Pustaka}

Bong, Soeseno, dkk. (2019). Manajemen Resiko, Krisis, \& Bencana untuk Industri Pariwisata yang Berkelanjutan. Jakarta: PT Gramedia Pustaka Utama.

Handerson, C. Joan. (2007). TourismCrisis : Causes, Consequences and Management. Elsevier : UK

Iriantara, Yosal. (2004). Manajemen Strategis Public Relations. Jakarta: Ghalia Indonesia. 
Jaques, T. (2009). Issue management as a post-crisis discipline: identifying and responding to issue impacts beyond the crisis. Journal Of Public Affairs (14723891), 9(1), 35-44

Kasali, Rhenald. (1994). Manajemen Public Relations: Konsep Dan Aplikasinya di Indonesia. Jakarta: Pustaka Utama Grafiti.

Koster, M. C., \& Politis-Norton, H. (2004). Crisis Management Strategies. Drug Safety, 27(8), 603-608.

Prayudi.(2008). Manajemen Isu - Pendekatan Public Relations. Yogyakarta: Pustaka Adipura.

Rangkuti, Freddy.(2015). Analisis SWOT : Teknik Membedah Kasus Bisnis. Jakarta : Gramedia Pustaka Utama

Revindo, Mohamad D, dkk. (2020). Briefing Note : Dampak Pandemi Covid-19 terhadap Pariwisata Indonesia: Tantangan, Outlook dan Respon KebijakanLembaga Penyelidikan Ekonomi dan Masyarakat, Fakultas Ekonomi dan Bisnis, Universitas Indonesia 